\title{
A escola, a pobreza, a distância e o trabalho infantil: o desafio da frequência na escola de primeiras letras da freguesia de São Bernardo (1830 - 1864)
}

\author{
Adriana Santiago* \\ Cláudia Panizzolo**
}

\section{Resumo}

No dia 17 de março de 1830 foi criada a primeira escola de Primeiras Letras na Freguesia de São Bernardo. Este artigo tem por objetivo compreender como se deu a implantação dessa escola identificando os desafios enfrentados, sobretudo em relação à frequência escolar das crianças. A pesquisa de cunho historiográfico tomou como fontes documentais os ofícios redigidos pelo professor e inspetor da escola, entre os anos de 1830 a 1864, que se encontram depositados no Arquivo do Estado de São Paulo. Buscou em Sharpe (2011) o aporte teórico com vistas a verificar as condições de funcionamento da primeira escola pública e os desafios enfrentados em relação ao acesso escolar, sobretudo pelas classes menos abastadas da sociedade. Como conclusão é possível afirmar que as condi-

* Mestranda em Educação pela Universidade Federal de São Paulo. Graduada em Letras e Pedagogia e Pós-graduada em Docência do Ensino Superior e Neuropsicopedagogia. É diretora escolar na rede municipal de ensino de São Bernardo do Campo. Membro do Grupo de Estudos e Pesquisas: Infância, Cultura e História-GEPICH. E-mail: santiago_adriana@yahoo.com.br.

** Doutorado em Educação: História, Política, Sociedade pela Pontifícia Universidade Católica de São Paulo. Professora Associada II da Escola de Filosofia, Letras e Ciências Humanas e Docente de Programa de Pós-Graduação em Educação da Universidade Federal de São Paulo. É líder do Grupo de Estudos e Pesquisa: Infância, Cultura e História-GEPICH. Pesquisadora do Grupo de Estudos e Pesquisa História da Educação, Imigração e Memória e do Grupo de Estudos e Pesquisa História da Educação: intelectuais, instituições, impressos. E-mail: claudia.panizzolo@unifesp.br 
cionantes econômicas e socioculturais impactaram a frequência dos alunos à primeira escola de São Bernardo.

Palavras-chave: São Bernardo; História da Educação; Escola de Primeiras Letras; Trabalho infantil; Crianças.

\section{School, poverty, distance and child labor: the frequency challenge at the school of first letters of the parish of São Bernardo (1830 - 1864)}

\section{Abstract}

On March 17, 1830, the first school of Primeiras Letras in the Freguesia de São Bernardo was created. This article aims to understand how this school was implemented, identifying the challenges faced, especially in relation to the school attendance of children. The historiographical research took as documentary sources the documents written by the teacher and inspector of the school, between the years 1830 to 1864, which are deposited in the Archive of the State of São Paulo. In Sharpe (2011) he sought the theoretical support in order to verify the operating conditions of the first public school and the challenges faced in relation to school access, especially by the less wealthy classes of society. As a conclusion, it is possible to state affirm that the economic and socio-cultural conditions impacted the attendance of students to the first school in São Bernardo.

Keywords: São Bernardo; History of Education; First Letters School; Child labor; Children.

\section{Escuela, pobreza, distancia y trabajo infantil: el desafío de frecuencias en la escuela de primeras letras de la parroquia de São Bernardo (1830-1864)}

\section{Resumen}

El 17 de marzo de 1830 se crea la primera escuela de Primeras Letras en la parroquia de São Bernardo. Este artículo tiene como objetivo comprender cómo se implementó esta escuela, identificando los desafíos enfrentados, especialmente en relación con la asistencia escolar de los niños. La investigación historiográfica tomó como fuentes documentales las cartas escritas por el maestro e inspector de la escuela, entre los años 1830 a 1864, que se encuentran depositados en el Archivo del Estado de São Paulo. En Sharpe (2011) buscó el aporte teórico para verificar las condiciones de funcionamiento de la primera escuela pública y los desafíos que enfrenta en rela- 
ción al acceso a la escuela, especialmente por las clases menos pudientes de la sociedad. En conclusión, es posible afirmar que las condiciones económicas y socioculturales impactaron la asistencia de los estudiantes a la primera escuela de São Bernardo.

Palabras clave: São Bernardo; Historia de la educación; Escuela de Primeras Letras; Trabajo infantil; Niños.

\section{Introdução}

O dia 17 de março de 1830 marcou o início de uma etapa importante na Freguesia de São Bernardo: o estabelecimento da primeira escola pública. Para essa escola, denominada de Primeiras Letras, estava destinada a função de ensinar os saberes elementares, dentre os quais se destacavam o ensino da leitura, escrita e operações matemáticas, além dos princípios de moral cristã e da doutrina da religião católica, apostólica romana. $\mathrm{Na}$ época, São Bernardo era uma Freguesia da Província de São Paulo, ou seja, uma divisão territorial urbana estabelecida a partir de uma paróquia erigida, sendo a menor divisão administrativa que poderia existir ${ }^{1}$.

A Lei Imperial de 15 de outubro de 1827, que regulamentou a proposta educacional brasileira, estabeleceu a criação de escolas de Primeiras Letras em todas as vilas e lugares onde houvesse população, possibilitando que a Freguesia de São Bernardo fosse contemplada com uma cadeira de Primeiras Letras (BRASIL, 1827).

Cabe recuperar que no início do século XIX a Freguesia era habitada por gente simples, pobre, com poucos recursos, em grande parte negros escravizados. Tratava-se de uma sociedade composta por trabalhadores rurais, cuja força de trabalho advinha de cultivar a terra e realizar transportes de produtos pela serra do mar (MARTINS, 1988).

Às crianças desta Freguesia foi ofertada a escola, mas era uma escola destinada apenas aos brancos e livres, isto porque as leis que regiam a Instrução Pública da época estabeleciam quem

De acordo com o dicionário on line de português, freguesia pode significar: distrito de uma paróquia; pequena povoação. Disponível em https://www. dicio.com.br/freguesia/, acesso em 10 jun. 2020. 
poderia ser matriculado na escola, a exemplo do Código de Instrução Pública da Província de São Paulo do ano de 1857, que em seu artigo 163 asseverava: "Não serão admitidos à matrícula, nem à frequência das escolas: $10^{\circ}$ Os escravos. $2 .^{\circ}$ Os que sofrem moléstias contagiosas" (SÃO PAULO, 1857, p. 27).

Em outras palavras, a escola de Primeiras Letras destinava-se prioritariamente para crianças brancas e livres, e poucas eram as que conseguiam frequentar as aulas, porque a cor da pele não se traduzia em condições sociais abastadas: era necessário o sustento para a sobrevivência, o trabalho não era opcional.

O presente artigo tem por objetivo compreender como se deu a implantação da primeira escola pública na Freguesia de São Bernardo, identificando os desafios enfrentados por ela, sobretudo em relação à frequência escolar das crianças, considerando três fatores preponderantes a pobreza, a distância entre a casa e a escola e o trabalho infantil. Para tanto, algumas questões foram levantadas: Quem eram as pessoas que moravam na Freguesia de São Bernardo? Onde estava localizada a escola? Quem frequentava as aulas de Primeiras Letras?

As fontes analisadas neste trabalho foram localizadas no Arquivo do Estado de São Paulo, nas caixas referentes à Instrução Pública da Província de São Paulo, na pasta da Secretaria dos Negócios do Interior. O presente artigo toma como fontes documentos $^{2}$ manuscritos do século XIX, que tratam sobre a primeira

Os documentos foram selecionados e transcritos, realizando-se uma classificação por assuntos, observando os sentidos que cada um apresentava para compor este trabalho. Em algumas citações diretas optou-se pelo uso de colchetes no meio do texto, a fim de indicar que não foi possível compreender uma ou mais palavras, contudo, analisando a relevância do documento e a possibilidade de se entender o sentido da escrita pelo seu próprio contexto, considerou-se viável a utilização. Considerou-se ainda apropriado manter alguns nomes grafados com letras iniciais maiúsculas, seguindo o mesmo formato que aparecem nos documentos analisados e observando o sentido de substantivo próprio dentro da escrita, pois nomeiam determinados setores, segmentos e locais, como foi o caso de "Instrução Pública", "Primeiras Letras"; "Freguesia"; "Província". Destaca-se que nas bibliografias estudadas não há consenso acerca da grafia dessas palavras, que ora se apresentam com letra maiúscula e por outras vezes minúsculas, dependendo do autor que as escreve. 
escola de Primeiras Letras, a saber, oito ofícios e o Relatório da Instrução Pública da Província de São Paulo do ano de 1861. A delimitação temporal deste texto tem como marco inicial 1830, data da criação da primeira escola de Primeiras Letras da Freguesia, e marco final, o ano de $1864^{3}$, último ano em que existia somente uma escola na região de São Bernardo.

Os procedimentos de pesquisa adotados foram pautados na revisão da literatura sobre História da Educação no período imperial e, particularmente em São Bernardo, considerando a delimitação temporal do artigo; levantamento e análise das principais legislações e reformas educacionais existentes no período estudado; levantamento, coleta e seleção de fontes.

A análise deste arcabouço documental possibilitou melhor compreensão dos desafios enfrentados desde a criação da primeira escola são-bernardense. Se por um lado havia uma escola pública criada para atender crianças, por outro lado cabe entender quais foram os motivos pelos quais a frequência e o abandono escolar não foram superados ao longo de 34 anos, delimitação temporal estudada, na Freguesia de São Bernardo.

Para tanto, busca-se sustentação para análise das fontes nos procedimentos apresentados por Sharpe (2011), com vistas a compreender os desafios de acesso à escola, sobretudo para as camadas populares, na perspectiva nomeada como história vista de baixo. Nas palavras do autor:

Essa perspectiva atraiu de imediato aqueles historiadores ansiosos por ampliar os limites de sua disciplina, abrir novas áreas de pesquisa e, acima de tudo, explorar as experiências históricas daqueles homens e mulheres, cuja existência é tão frequentemente ignorada, tacitamente aceita ou mencionada apenas de passagem na principal corrente da história (SHARPE, 2011, p. 41).

3 Em 14 de março de 1865 foi criada a primeira escola de Primeiras Letras de São Bernardo destinada ao sexo feminino. 
De acordo com Sharpe (2011) esse importante olhar para as pessoas que, por muitas vezes, não foram foco de atenção de historiadores, faz com que recordemos que a identidade de um povo não foi estruturada apenas por classes em ascensão social e econômica.

O texto está organizado em duas seções e considerações finais. A primeira seção intitulada A escola de Primeiras Letras da Freguesia de São Bernardo, aborda a criação da escola na Freguesia, assim como procura elucidar o contexto social da época, seus desafios e fatores locais que influenciaram no estabelecimento da primeira instituição escolar pública. A segunda seção, intitulada $A$ frequência escolar, a pobreża, a distância e o trabalho infantil: necessidades em pauta, se propõe a analisar as fontes identificando através delas os desafios enfrentados pelas crianças para frequentarem a primeira escola pública de São Bernardo.

\section{A escola de primeiras letras da freguesia de São Bernardo}

A primeira escola da Freguesia de São Bernardo funcionava em um cômodo que ainda estava em construção, de propriedade do professor, em condições precárias em relação à estrutura física e com escassez de materiais. Durante 35 anos foi a única escola da Freguesia, que a partir de 1865 passou a contar com outras escolas de Primeiras Letras em seu território.

Localizada no atual município de São Bernardo do Campo, a escola teve como professor de Primeiras Letras o padre Thomaz Innocencio Lustosa. De acordo com o ofício encaminhado ao Inspetor Geral da Instrução Pública em 13 de março de 1852, escrito pelo padre-professor, suas aulas aconteciam em sua própria residência e eram frequentadas, em média, por 20 a 30 alunos, sobre os quais regularmente encaminhava relatórios ao Inspetor Geral da Província de São Paulo, informando frequência e aproveitamento de aprendizagem. Nesse mesmo ofício é possível identificar a precariedade de funcionamento no tocante à estrutura física e materiais: 
[...] Releva a informar a V.Sa. o seguinte: A aula nos dias compridos de manhã entra às 8 horas e acabam as 10 e meia, a tarde entra as 2 acabam-se as 4 e meia, nos dias lentos entram as 8 e acaba-se as 11 de tarde entra a 1 e meia e acaba as 4 para alguns alunos que moram mais longe terem tempo de com o dia chegarem a suas casas. [...]. Os trabalhos que os alunos escrevem nas impressões é a minha custa que tenho mandado vir de [...] para eles escreverem. Tenho adaptado manuscritos e cartas de manhãs e impressos para tarde. Assim é pouco ensinada gramática nacional porque os pais apenas os filhos mal sabem ler escrever e algumas contas, logo tiram da aula, muitas vezes sem que o professor saiba e por isso não posso ensinar gramática. [...] As correções que costumo empregar são físicas e morais. A sala existe a aula é a minha casa, que ainda não está acabada no todo, não moro nela, contudo a sala apesar de ainda não estar forrada é suficiente para cômodo dos alunos. Tenho mais a informar V.Sa. não tenho livro de matrícula nem mobília pertencente à aula, só sim existem 1 banco de 10 palmos, 1 mesa pequena e 1 cadeira [...] por isso não posso enviar a V.Sa. as outras relações minuciosas mencionadas em vosso ofício (LUSTOSA, 1852, p. 1, grifo nosso).

Apesar da primeira escola de Primeiras Letras em São Bernardo ser apenas para meninos, Lustosa também lecionava para meninas, o que se constata através das fontes analisadas, em que o professor informa ao Inspetor Geral da Instrução Pública a quantidade de meninas que frequentava sua turma, indicando a necessidade da criação de uma cadeira de Primeiras Letras para meninas. Consta em Relatório de 30 de setembro de 1861 a seguinte informação: "Em cumprimento ao que por vossa senhoria me foi ordenado em portaria circular $n^{\circ} 473$ de 10 do corrente, tenho a dizer o seguinte: 1. Que há muito tenho sempre ensinado ambos os sexos; [...]" (LUSTOSA, 1861, p. 1).

De acordo com o Relatório de Instrução Pública de $1861^{4}$, havia autorização para o padre Lustosa lecionar para meninas, sendo que as características atribuídas para tal foram as seguintes: "posição, idade, caráter e desvelo". Ainda a respeito da autorização o ofício datado de 10 de abril de 1864, escrito por Francisco Martins

\footnotetext{
4 Disponível no Arquivo do Estado de São Paulo - Inspetoria Geral da Instrução Pública de S. Paulo. Relatório. 1861. Páginas 23 e 24.
} 
Bonilha, Inspetor de Ensino de São Bernardo, indica que especificamente Lustosa teria esta permissão ao afirmar que:

\begin{abstract}
Não há presentemente nesta mesma Freguesia escola de primeiras letras para o sexo feminino, nem particular, e muito menos pública, o que é bem sensível, sendo que no tempo do professorado do hoje vigário colado Padre Thomaz Innocencio Lustosa lhe era concedido lecionar também às meninas, o que se não tem facultado ao nosso professor, sendo ele casado, e vivendo honestamente com sua mulher [...] (BONILHA, 1864, p. 1).
\end{abstract}

Todavia, apesar das meninas frequentarem as aulas, ao verificar os relatórios de frequência é possível identificar na lista a predominância dos nomes masculinos, como é o caso da relação de alunos encaminhada pelo padre Lustosa ao Inspetor Geral da Instrução Pública em 1834, em que os nomes aparecem na seguinte ordem no documento original: Salvador Pires de Lima, Jozé Theodoro de Barros, Francisco M. Galvão, Jozé M. Galvão, Joaquim Queiros, Jozé Leite Vieira, Jozé Pia, Joaquim Pereira... (LUSTOSA, 1834, p. 1). O total são 22 alunos na relação, todos do sexo masculino, sendo que alguns dos nomes encontram-se ilegíveis no documento original, razão pelo qual não foi possível mencionar o nome de todos.

O ofício datado de 25 de agosto de 1856 em que Lustosa afirma que 31 meninos estavam matriculados e que 8 meninas frequentavam as aulas de Primeiras Letras, aponta novamente para o quantitativo de meninas, observando-se que era inferior ao de meninos:

Em cumprimento a portaria de V.Sa n ${ }^{\circ} 628$ de 08 do corrente remeto V.Sa a informar que ordena: [...] que estão matriculados 39 alunos incluindo 8 alunas, sendo o número dos que frequentam 30 às vezes 27,28 . Hoje contei 31 alunos na [...] da chamada. No fim do ano próximo não ocorrerão exames por não estarem suficientes para isso (LUSTOSA, 1856, p.1).

Os dados acerca da frequência eram informados à Inspetoria Geral da Instrução Pública de São Paulo pelo professor Lustosa e por Francisco Martins Bonilha, que foi Inspetor de Ensino da Freguesia durante anos. 
Francisco Martins Bonilha exercia um posto militar, equivalente ao atual de segundo-tenente, o que lhe deu a patente de alferes. Exerceu vários cargos importantes em São Bernardo, entre eles de fabriqueiro, cuja função era recolher os rendimentos da igreja, assim como administrar o patrimônio e zelar por sua conservação. Também atuou como fiscal suplente, juiz de paz e inspetor de ensino (SANTOS, 1992, p. 237).

Há indícios que a patente de Bonilha possa ter sido um dos critérios para a indicação do cargo, realizada pelo Presidente da Província. Paulo e Warde (2015) afirmam que nos municípios, em regra, eram indicados para a função de Inspetor Distrital indivíduos ligados à Igreja ou ao Exército, ou ainda cidadãos graduados.

Bonilha foi um dos homens mais poderosos e temidos da Freguesia de São Bernardo, sendo possível afirmar que também era uma pessoa de muitas posses, dentre elas uma fábrica de chá, uma das maiores da Província de São Paulo, que demandava o trabalho de pessoas escravizadas (MARTINS, 1988). Outro dado mencionado pelo autor é que em 1838 mais de metade da população da Freguesia de São Bernardo era escravizada trazida da África, uma vez que no município não havia braços suficientes para o trabalho, sendo os motivos elucidados pelo autor da seguinte forma:

Porém há outra explicação para esse número anormal de escravos africanos no lugar, em desproporção com o número de escravos crioulos, isto é, negros nascidos no Brasil. Refiro-me à alta mortalidade de escravos e a sua baixa natalidade na região. Em 1838, a proporção de casamentos entre escravos foi mais alta do que entre livres. Porém o número de nascimentos entre escravos foi quatro vezes menor do que entre livres. E houve 5.8\% de mortos entre os escravos e apenas 3.6 entre os livres. Esses dados mostram com clareza que eram muito más as condições de vida dos escravos de São Bernardo, nascendo poucos e morrendo muitos. Era necessário, portanto, trazer novos escravos para substituí-los, no caso, africanos (MARTINS, 1988, p. 17).

A respeito da população livre e escrava de São Bernardo foi realizado um registro pelo Marechal Daniel Pedro Müller no censo 
da Província, publicado em 1838, cujos dados apontavam que "[...] pouco mais da metade da população de São Bernardo não era branca $(56,2 \%)$. E que quase metade da população livre não era branca. Ou seja: havia quase tantos negros e pardos livres quantos eram brancos" (MARTINS, 1988, p. 17). Cabe destacar que com o passar dos anos foi verificado o desaparecimento das pessoas escravizadas, que passam a representar um percentual menor nos dados populacionais (Tabela 1).

Tabela 1: População de São Bernardo em 1836, 1838 e 1874

\begin{tabular}{|c|c|c|c|c|}
\hline Ano & Livres & Escravos & Total & $\begin{array}{c}\text { Percentual de pessoas } \\
\text { escravizadas }\end{array}$ \\
\hline 1836 & 1.001 & 406 & 1.407 & $28.9 \%$ \\
\hline 1838 & 1.001 & 346 & 1.347 & $25.7 \%$ \\
\hline 1874 & 2.568 & 119 & 2.687 & $4.4 \%$ \\
\hline
\end{tabular}

Fonte: MARTINS, 1988, p. 16

Para atender as crianças pertencentes a essa população, em grande parte de origem humilde, foi criada a primeira escola pública da Freguesia, contudo, de acordo com Santos (1992) no ano de 1853 João José de Oliveira realizou um quadro demográfico da Freguesia de São Bernardo, indicando que existiam 1.300 moradores, "calculando-se em 100 meninos e outras 100 meninas" (p. 203). Destaca-se que no ano anterior à realização do quadro demográfico, em 1852, existiam 26 alunos matriculados na escola de Primeiras Letras da Freguesia.

Apesar do crescimento populacional e da criação de novas escolas a partir de 1865, ainda era significativo o número de crianças que não frequentavam a escola. O recenseamento geral do Brasil do ano de 1872 (tabela 2) confirma que a situação perdurou na Freguesia, indicando que a situação não se restringiu ao período delimitado desse trabalho 
Tabela 2: Situação escolar, 1872

\begin{tabular}{|c|c|c|c|c|c|c|c|}
\hline \multirow[b]{2}{*}{ Condições } & \multirow[b]{2}{*}{ Sexos } & \multirow[b]{2}{*}{ Almas } & \multirow[b]{2}{*}{$\begin{array}{l}\text { Sabiam ler } \\
\text { e escrever }\end{array}$} & \multirow[b]{2}{*}{ Analfabetos } & \multicolumn{3}{|c|}{ População escolar de 6 a 15 anos } \\
\hline & & & & & $\begin{array}{c}\text { Fre- } \\
\text { quentam } \\
\text { escolas }\end{array}$ & $\begin{array}{l}\text { Não fre- } \\
\text { quentam } \\
\text { escolas }\end{array}$ & Total \\
\hline \multirow{3}{*}{ Livres } & Homens & 1277 & 219 & 1058 & 43 & 271 & 314 \\
\hline & Mulheres & 1291 & 66 & 1225 & 19 & 365 & 384 \\
\hline & Soma & 2568 & 285 & 2283 & 62 & 636 & 698 \\
\hline \multirow{3}{*}{ Escravos } & Homens & 68 & --- & 68 & --- & --- & --- \\
\hline & Mulheres & 51 & --- & 51 & --- & --- & --- \\
\hline & Soma & 119 & --- & 119 & --- & --- & --- \\
\hline \multicolumn{2}{|c|}{ Soma geral } & 2687 & 285 & 2402 & 62 & 636 & 698 \\
\hline
\end{tabular}

Fonte: Recenseamento Geral do Brasil 1872

A partir dos levantamentos realizados, a frequência escolar na primeira escola da Freguesia de São Bernardo se apresenta como um desafio, cujas possíveis causas serão tratadas na próxima seção.

\section{A frequência escolar, a pobreza, a distância e o trabalho infantil: necessidades em pauta}

A garantia da frequência das crianças às aulas foi um grande, senão o maior, desafio para o sucesso escolar em São Bernardo. No relatório endereçado ao Inspetor Geral da Instrução Pública, datado de 1832 há uma coluna intitulada frequência, em que é possível identificar a anotação do padre-professor Lustosa indicando que determinados alunos "tem tido algumas faltas", sobre os quais na coluna seguinte intitulada aproveitamento o professor indica que "começando o abc agora [...] começa sofrível em contas de dividir" (LUSTOSA, 1832, p. 1). Sendo assim é possível afirmar, a partir das informações contidas no relatório, que a frequência escolar era um desafio para muitas crianças.

A mesma situação foi localizada no Relatório de Frequência encaminhado por Lustosa em agosto de 1839 (figura 1), em que relata que "A pouca frequência de alguns destes alunos é a causa de não estarem mais adiantados" (LUSTOSA, 1839, p. 1). 


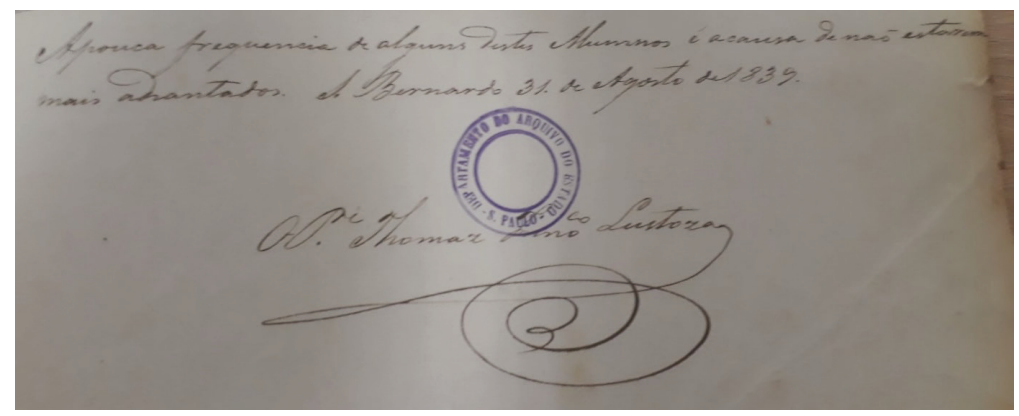

Figura 1: Observações no mapa de alunos - agosto de 1839

Fonte: Arquivo Público do Estado de São Paulo. Ordem 5.098

A baixa frequência atrelada à pobreza e necessidade de trabalho é denunciada por Bonilha no ano de 1864, quando presta informações à Câmara de São Paulo, relatando a situação da baixa frequência em consequência da necessidade de os pais empregarem seus filhos:

Em cumprimento a circular de V.Sa de 12 de agosto do corrente ano, faço chegar às mãos de V.Sa o mapa [...] a relação dos alunos da escola de primeiras letras desta Freguesia, pelo qual verá V.Sa o número dos matriculados que são de 38 e ordinariamente frequentam menos de 20, isso pela omissão dos pais que se desculpam com o seu estado de pobreza por cuja causa são ocupados serviços da casa. Da mesma maneira verá V.Sa. o estado de adiantamento de cada um deles (BONILHA, 1864, p. 1, grifo nosso).

A necessidade do trabalho infantil estava intimamente relacionada à situação econômica da população, o que se constata no ofício escrito por Lustosa em 24 de novembro de 1849, ao falar da pobreza dos pais das crianças:

Cumprindo com que vossa excelentíssima me ordenou em Portaria de 29 p.p., remeto a vossa excelentíssima a relação inclusa dos alunos que frequentam a minha aula de primeiras letras. Releva dizer a vossa excelentíssima que há grande falta de frequência em alguns alunos, e por isso não 
estão mais adiantados; entretanto há outros alunos que não trazem os utensílios necessários por causa da grande pobreza dos pais, o que levo ao conhecimento de vossa excelentíssima para dar as providências necessárias a bem dos meninos (LUSTOSA, 1849, p. 1).

No ofício encaminhado ao Dr. Diogo de Mendonça Pinto, Inspetor Geral da Instrução Pública da Província de São Paulo, datado de 13 de março de 1852, é notória a preocupação do professor em relação a aprendizagem, que estava atrelada ao abandono escolar ao afirmar que "[...] a muito poucos tenho ensinado Gramática Nacional porque os pais apenas os filhos mal sabem ler e escrever e algumas contas, logo os tiram da aula. Muitas vezes sem que o professor saiba. Por isso não posso ensinar gramática" (LUSTOSA, 1852, p. 1).

Em 1842 foi relatado através de ofício à Província de São Paulo, escrito por Bonilha, que a baixa frequência também era responsabilidade do professor. Não são mencionados especificamente os motivos pelos quais recaem sobre Lustosa a responsabilidade da ausência dos alunos, uma vez que o Inspetor de Ensino apenas menciona o estado de sua aula. Todavia o teor do documento expressa bastante insatisfação em relação ao padre-professor:

Transmito a V.Sa. a relação inclusa do professor de primeiras letras desta Freguesia, a qual não satisfaz os quesitos exigidos em seu ofício. Pois que faltando a filiação dos alunos não se pode ajuizar se eles são reais ou quiméricos. Na minha informação do ano próximo passado já disse o que entendia sobre este professor, e sobre o estado de sua aula, ordinariamente frequentada por três ou quatro meninos. E por isso me refiro à dita informação, restando-me somente acrescentar que esta Freguesia pouco ou nada perderia com a extinção desta escola (BONILHA apud SANTOS, 1992, p. 202).

Por sua vez, o padre Lustosa também relata outras dificuldades em garantir a frequência dos alunos, dentre elas a distância, afirmando que esta seria um impeditivo para o acesso e permanência das crianças, somado às questões econômicas e necessidade de trabalho. Cabe recuperar que até a década de 90 do século XIX, a 
região de São Bernardo era composta por municípios da atual região do ABC Paulista ${ }^{5}$, sendo elevada a extensão territorial são-bernardense, ou seja, a distância a ser percorrida pelas crianças era grande e um dificultador para frequentarem a aula de Primeiras Letras. Nesse sentido, com vistas a garantir a frequência dos alunos, o padre-professor realizou algumas ações, dentre elas uma adaptação de horário, conforme já mencionado no ofício datado de 13 de março de 1852.

Ainda no ofício encaminhado pelo professor Lustosa, em 13 de março de 1852, endereçado ao Inspetor Geral da Instrução Pública da Província, Diogo de Mendonça Pinto, os limites para a concretização de ensino de qualidade são elucidados pelo padre, ao relatar que:

[...] o catecismo que os alunos aprendem é o histórico de Fleury, traduzido pelo Dr. Manoel Joaquim do Amaral Gurgel, cujos exemplares me foram remetidos pelo Exmo. Governo há muitos anos. Por isso que se acham sujos e estragados (LUSTOSA, 1852, p. 1).

Para além da frequência, o que era ofertado às crianças quando essas compareciam às aulas carecia de maior investimento, pois eram materiais velhos e em condições precárias de conservação.

A partir da necessidade de justificativa do professor, pode-se afirmar que as cobranças por parte da Inspetoria Geral da Instrução Pública de São Paulo eram efetivas, indicando a centralidade de poder, assim como observa-se como se dava a comunicação entre Freguesia e Província no tocante aos assuntos relacionados à escola.

Observa-se ainda no mesmo ofício, datado de 13 de março de 1852, a informação que as aulas ocorriam na casa do professor Lustosa, que afirmava que apesar da casa não estar apta para morar,

De acordo com o Consórcio Intermunicipal Grande $\mathrm{ABC}$ a região conhecida como Grande $\mathrm{ABC}$ ou ainda como ABC Paulista está inserida a sudeste da Região Metropolitana de São Paulo e é composta por sete municípios: Santo André, São Bernardo do Campo, São Caetano do Sul, Diadema, Mauá, Ribeirão Pires e Rio Grande da Serra. Disponível em https://consorcioabc.sp.gov. br/. Acesso em 13 out. 2021. 
servia para dar aula. Esta afirmação indica que para a estrutura física escolar o mínimo era suficiente.

Nesse sentido, pode-se recorrer a Faria Filho (2016) para compreender a educação brasileira ao longo do século XIX, que segundo o autor, assumia características de uma luta do governo do estado contra o governo da casa, e que resultou no afastamento das "tradições culturais e políticas a partir das quais o espaço doméstico organizava-se e dava a ver” (p. 146).

No entanto, essa nova organização ainda caminhava a passos lentos na Freguesia de São Bernardo, uma vez que não apenas o espaço físico onde funcionava a escola de Primeiras Letras, mas também os materiais pedagógicos eram insuficientes, o que foi objeto de queixa por parte do professor.

Lustosa lamenta ainda a falta de comunicação com as famílias, ao afirmar que muitas vezes nem ficava sabendo que as crianças deixariam de frequentar a escola, o que nos remete a uma relação pouco próxima com as famílias dos alunos atendidos por ele.

É possível afirmar que poucas foram as crianças que frequentaram as aulas de Primeiras Letras. Ficaram de fora, ao que parece, sobretudo as crianças que eram, em sua maioria, pobres e trabalhadoras. Trazer à memória as minorias que compuseram a História de São Bernardo ajudam a "convencer aqueles de nós, nascidos sem colheres de prata em nossas bocas, de que temos um passado, de que viemos de algum lugar" (SHARPE, 2011, p. 63).

Importante ressaltar que não foram localizados nos ofícios analisados qualquer tipo de reinvindicação de melhorias das condições de vida que as pessoas da Freguesia de São Bernardo levavam, seja de cunho de ajuda financeira pela Província de São Paulo, ou investimento em moradias e trabalho, o que sugere que a situação estava confortável de certa forma a quem representava a Instrução Pública na Freguesia ou ainda, a aprovação das próprias condições em si poderiam ser benéficas, por interesses que os contemplassem.

Apesar das informações contidas sobre a pobreza das famílias, a necessidade de trabalho das crianças e a baixa frequência às 
aulas, há com reincidência nos documentos analisados as informações de que não havia outra escola na região, que crianças estavam fora da escola, que as matriculadas não compareciam com a devida decência às aulas, mas, nos mesmos ofícios onde eram explicitados os problemas, continha a informação de que não havia ocorrência de fatos importantes, não sendo necessárias quaisquer providências.

\section{Considerações finais}

A pesquisa sobre a história da educação da Freguesia de São Bernardo, apontou para situações estruturais, econômicas e socioculturais que tiveram impacto profundo na frequência escolar, considerando que poucas crianças foram atendidas na escola, para as quais o limite da própria sobrevivência está intimamente ligada à pobreza e necessidade de trabalho, não permitiu que avançassem e partilhassem da aspiração que a civilização por meio das escolas de Primeira Letras propunha, que seria formar um Estado-Nação com valores que exaltassem a Pátria recém independente.

O grande número de escravizados, por exemplo, provocou uma discussão de como as diferenças sociais foram se constituindo na cidade. Novamente busca-se em Sharpe (2011) apoio para compreender o que acontecia na Freguesia. O autor em seu texto faz menção à possibilidade de ação reparatória, ou seja, contemplar sujeitos excluídos ao longo da história ao se investigar grupos marginalizados, o que acalenta esta escrita, de forma a contribuir para uma denúncia social, cujo lamento ecoa há séculos. Em suas palavras:

[...] A importância da história vista de baixo é mais profunda do que apenas propiciar aos historiadores uma oportunidade para mostrar que eles podem ser imaginativos e inovadores. Ela proporciona também um meio para reintegrar sua história aos grupos sociais que podem ter pensado tê-la perdido, ou que nem tinham conhecimento da existência de sua história (SHARPE, 2011, p. 60).

Nessa perspectiva asseverada por Sharpe (2011) é possível reintegrar à História são-bernardense as classes menos abastadas, 
através da identificação das razões que influenciaram as tomadas de decisão por parte das famílias frente aos desafios em garantir a frequência dos filhos à escola e, ao mesmo tempo, problematizar a ausência de providência por parte do governo provincial em relação às melhorias e investimentos ao longo do século XIX na escola pública de São Bernardo e, ao que parece, em relação à população não foi diferente.

Bloch (2002) aborda o papel do historiador não como um inquisidor, mas como aquele que busca compreender o tempo, problematizando e colocando em crise a própria história. Nesse sentido, as fontes analisadas proporcionaram a abertura de um diálogo acerca de como a primeira escola se estabeleceu na Freguesia de São Bernardo, considerando a pobreza, a distância e o trabalho infantil, somados à escassez de recursos materiais e estruturais da escola como fatores preponderantes para as dificuldades de acesso e permanência dos alunos.

Considerar a sociedade são-bernardense da época, com uma situação histórica escravagista, somada às condições econômicas, desafia a pensar que a escola foi para poucos. Faria Filho, Lopes e Veiga (2016) afirmam que "em um país cuja memória e patrimônio educacionais são diariamente dilapidados, a pesquisa histórica é também uma forma positiva de intervenção social” (p. 15). Nesta perspectiva, compreender a História da Educação de São Bernardo pressupõe esperançar gerações por vir.

\section{Referências}

BLOCH, M. Apologia da história ou o ofício de historiador. Rio de Janeiro: Jorge Zahar Editor Ltda, 2002.

BONILHA, F. M. Ofício apresentado ao Inspetor Geral da Instrução Pública da Província de São Paulo pelo Inspetor de Ensino, Freguesia de São Bernardo, em 10 de abril de 1864, Arquivo Público do Estado de São Paulo, Caixa Ordem 5.098.

BRASIL, Coleção das Leis do Império do Decreto Lei de 15 de outubro de 1827. Disponível em <https://www2.camara.leg.br/legin/fed/lei_sn/1824- 
1899/lei-38398-15-outubro-1827-566692-publicacaooriginal-90222-pl.html>. Acesso em: 16 fev. 2021.

LUSTOSA, T. I. Ofício apresentado ao Inspetor Geral da Instrução Pública da Província de São Paulo pelo Professor Público, 1. ${ }^{a}$ cadeira do sexo masculino da Freguesia de São Bernardo, em 1832, Arquivo Público do Estado de São Paulo, Caixa Ordem 5.098.

LUSTOSA, T. I. Ofício apresentado ao Inspetor Geral da Instrução Pública da Província de São Paulo pelo Professor Público, 1. ${ }^{a}$ cadeira do sexo masculino da Freguesia de São Bernardo, em 1834, Arquivo Público do Estado de São Paulo, Caixa Ordem 5.098.

LUSTOSA, T. I. Ofício apresentado ao Inspetor Geral da Instrução Pública da Província de São Paulo pelo Professor Público, 1. ${ }^{a}$ cadeira do sexo masculino da Freguesia de São Bernardo, em agosto de 1839, Arquivo Público do Estado de São Paulo, Caixa Ordem 5.098.

LUSTOSA, T. I. Ofício apresentado ao Inspetor Geral da Instrução Pública da Província de São Paulo pelo Professor Público, 1. ${ }^{\mathrm{a}}$ cadeira do sexo masculino da Freguesia de São Bernardo, em 24 de novembro de 1849, Arquivo Público do Estado de São Paulo, Caixa Ordem 5.098.

LUSTOSA, T. I. Ofício apresentado ao Inspetor Geral da Instrução Pública da Província de São Paulo pelo Professor Público, 1. ${ }^{a}$ cadeira do sexo masculino da Freguesia de São Bernardo, em 13 de março de 1852, Arquivo Público do Estado de São Paulo, Caixa Ordem 5.098.

LUSTOSA, T. I. Ofício apresentado ao Inspetor Geral da Instrução Pública da Província de São Paulo pelo Professor Público, 1. ${ }^{a}$ cadeira do sexo masculino da Freguesia de São Bernardo, em 25 de agosto de 1856, Arquivo Público do Estado de São Paulo, Caixa Ordem 5.098.

LUSTOSA, T. I. Ofício apresentado ao Inspetor Geral da Instrução Pública da Província de São Paulo pelo Professor Público, 1. a cadeira do sexo masculino da Freguesia de São Bernardo, em 30 de setembro de 1861, Arquivo Público do Estado de São Paulo, Caixa Ordem 5.098.

FARIA FILHO, L. M. Instrução elementar no século XIX. In: LOPES, E. M. T.; FARIA FILHO, L. M; VEIGA, C. G. (orgs). 500 anos de educação no Brasil. Belo Horizonte: Autêntica, 2016, p. 135-151. 
MARTINS, J. S. A escravidão em São Bernardo, na colônia e no império. São Bernardo do Campo: CEDI, 1988.

PAULO, M. A. R.; WARDE, M. J. A estrutura administrativo-burocrática da instrução pública paulista instituída pelo regulamento de 08 de novembro de 1851 . Cadernos de História da Educação. Uberlândia, MG, v. 14. V.1, jan-abr. 2015, p. 279-300.

SANTOS, W. S. Antecedentes históricos do ABC Paulista: 1550-1892. São Bernardo do Campo: SECE, 1992.

SÃO PAUlO. Relatório da Instrução Pública da Província de São Paulo, 1861, Arquivo Público do Estado de São Paulo. Disponível em http://www.arquivoestado.sp.gov.br/site/acervo/repositorio_digital/relatorios_educacao. Acesso em: 17 fev. 2021.

SÃO PAUlO. Código de Instrução Pública da Província de São Paulo do ano de 1857, Arquivo Público do Estado de São Paulo. Disponível em http:// www.arquivoestado.sp.gov.br/site/acervo/repositorio digital/relatorios educacao. Acesso em 17 fev. 2021.

SHARPE, J. A história vista de baixo. In: BURKE, Peter (org.). A Escrita da História: novas perspectivas. São Paulo: Editora UNESP, 2011. 